\title{
Creating genetic reports that are understood by nonspecialists: a case study
}

\author{
Gabriel Recchia, PhD (1) ${ }^{1}$, Antonia Chiappi, BSC (1) ${ }^{2}$, Gemma Chandratillake, PhD, CGC (10) ${ }^{2,3}$, \\ Lucy Raymond, MA, DPhil FRCP ${ }^{3,4,5}$ and Alexandra L. J. Freeman, MA, DPhil (1) ${ }^{1}$
}

Purpose: Guidelines recommend that genetic reports should be clear to nonspecialists, including patients. We investigated the feasibility of creating reports for cystic fibrosis carrier testing through a rapid user-centered design process that built on a previously developed generic template. We evaluated the new reports' communication efficacy and effects on comprehension against comparable reports used in current clinical practice.

Methods: Thirty participants took part in three rounds of interviews. Usability problems were identified and rectified in each round. One hundred ninety-three participants took part in an evaluation of the resulting reports measuring subjective comprehension, risk probability comprehension, perceived communication efficacy, and other factors, as compared with standard reports.

Results: Participants viewing the user-centered reports rated them as clearer, easier to understand, and more effective at communicating key information than standard reports. Both groups ended up with equivalent knowledge of risk probabilities, although we observed differences in how those probabilities were perceived.

Conclusion: Our findings demonstrate that by starting with a patient-friendly generic report template and modifying it for specific scenarios with a rapid user-centered design process, reports can be produced that are more effective at communicating key information. The resulting reports are now being implemented into clinical care.

Genetics in Medicine (2020) 22:353-361; https://doi.org/10.1038/s41436019-0649-0

Keywords: genetic test reports; comprehension; user-centered design; risk communication; personalized medicine

\section{INTRODUCTION}

Genetic and genomic testing is becoming increasingly widely available due to falling costs of testing, new referral pathways, increased integration of such testing into mainstream clinical practice, and other initiatives such as the National Health Service (NHS) Long Term Plan and the Improving Outcomes through Personalised Medicine effort in the United Kingdom. ${ }^{1}$ As access to such services expands, nonspecialist clinicians are increasingly tasked with explaining the results of these tests to patients. In some cases, patients may be faced with the prospect of interpreting reports themselves without guidance. For example, patients in some countries can obtain copies of their test results directly from testing laboratories. ${ }^{2}$

Research suggests that even clinicians have difficulties understanding genetic reports, ${ }^{3,4}$ and many researchers have recognized the need for clearer reports in light of variability among individuals in numeracy, health literacy, and genetic literacy. ${ }^{2,5,6}$ Guidelines state that reports should be clear and comprehensible to nonspecialists, and provide some guidance on how to achieve this. ${ }^{2,7-14}$ Despite widespread adoption of some guidelines, such as those of the American College of Medical Genetics and Genomics (ACMG), ${ }^{7}$ studies investigating patients' and nonspecialists' satisfaction and perceptions find that existing reports leave substantial room for improvement. ${ }^{4,15-17}$ Genomic reports are especially challenging due to lack of standardization ${ }^{18,19}$ and the complexity and uncertainty of the information involved. ${ }^{20}$

There have been attempts to make the interpretation of laboratory reports clearer to nonspecialist clinicians, ${ }^{16,21-25}$ but far fewer to make them clearer to patients. In 2014, Haga et $\mathrm{al}^{2}$. noted that "only one study has described efforts to develop a patient-friendly pathology report" (p. 4). There have since been some efforts to make genetic or genomic test reports more patient-friendly, ${ }^{2,14,26-30}$ including in the directto-consumer (DTC) industry. ${ }^{5,30}$ However, work of this kind still appears rarely outside the DTC space, and there has been little published (or made publicly available) about the development of DTC reports. There are therefore few

\footnotetext{
${ }^{1}$ Winton Centre for Risk and Evidence Communication, University of Cambridge, Cambridge, UK; ${ }^{2}$ Institute of Continuing Education, University of Cambridge, Cambridge, UK; ${ }^{3}$ East of England NHS Genomic Medicine Centre, London, UK; ${ }^{4}$ Department of Medical Genetics, University of Cambridge, Cambridge, UK; ${ }^{5}$ NIHR Bioresource-Rare Disease, London, UK. Correspondence: Gabriel Recchia (glr29@cam.ac.uk)
} 
examples to guide the design and evaluation of a patientfriendly genetic report.

In industry, it is common for new products to be developed via a user-centered design ${ }^{31,32}$ approach whereby changes are made in an iterative process, taking into account the context in which the product will be used, key requirements, and feedback from users. Typically, multiple rounds of evaluation are conducted, monitoring metric(s) of interest (e.g., number and severity of usability issues, time required for users to accomplish a task, etc.) to assess what changes are needed. The iterative process continues until some stopping criterion is reached.

With rare exceptions, ${ }^{25,28}$ user-centered design is not generally used as a guiding framework in the context of noncommercial genetic report development. Our aim was to determine whether such a process could be used to efficiently produce genetic report templates suitable for implementation. If such reports could be shown to communicate more effectively to laypersons, this would suggest a reasonable, cost-efficient approach that could be emulated by others.

Our approach was to split the design phase into two. In a first stage, patients, nonspecialist clinicians and genetic testing experts participated in the development of a report template for a fictional genetic condition. This work (submitted for publication) resulted in a generic template that could be adapted to specific use cases. We chose cystic fibrosis (CF) carrier testing as our specific use case as primary care physicians were being directed to order CF tests (and hence receive and communicate results) in our local health-care region. There was therefore a need to ensure that reports from such testing were clear to nonspecialist readers. Our study provides preliminary findings regarding benefits and limits of what can be expected from a design process of this kind.

\section{MATERIALS AND METHODS}

One design feature of the generic template was to accommodate the needs of both genetic specialists and nonspecialists (including patients) by separating sections containing technical information from those in "plain English." Therefore, our reports had both a "patient-centered" page and a "clinician-centered" page, with the second page intended for health professionals.

Five two-page draft reports were developed representing common scenarios for CF carrier testing, where the reasons for referral were the following: partner heterozygous for p.Phe508del (positive and negative); familial p.Phe508del (positive and negative); and family history (unknown variant), negative report only. Reasons for referral were stated in simpler language on the patient-centered page of each report. Our initial reports were developed on the basis of our previously designed generic report template, with input from members of a working group who produced recommendations based on a revision of the Association for Clinical Genomic Science general reporting guidelines. This group included members of the Regional NHS Clinical Genetics Laboratory in Cambridge, clinical geneticists, genetic counselors, National
External Quality Assessment Service members, and other experts in the reporting of genetic test results.

User-centered testing can take a formative or summative approach. Formative testing is conducted iteratively while a product is still in development, whereas summative testing is done once the stopping criterion has been met and the design finalized. Their goals differ accordingly: whereas "formative testing focuses on identifying ways of making improvements, summative testing focuses on evaluating against a set of criteria". ${ }^{33}$ All five reports were subject to formative testing, and two were selected for summative testing, namely those having "partner heterozygous for p.Phe508del" as the reason for referral (Figs. S1, S2; sample patient-centered page in Fig. 1). Corresponding anonymized "standard" report templates currently in use were obtained from Yorkshire and North East Genomic Laboratory Hub Central Laboratory to act as a control comparison (Figs. S3, S4), with permission. Information that could have been used to identify the laboratory that the templates came from was fictionalized. Informed consent was obtained from all participants. This study received ethical approval from the Cambridge Psychology Research Ethics Committee (PRE.2018.077).

\section{User-centered design process Interviews}

Three rounds of semistructured interviews were conducted over Skype with a convenience sample of 30 volunteers recruited from the Cambridge Rare Disease Network, individuals who had participated in previous studies, and researcher contacts. Twelve, eight, and ten volunteers participated in each round, respectively. Volunteers were compensated with Amazon vouchers for $£ 10$. Interviews included questions pertaining to communication efficacy and subjective comprehension (e.g., questions about reports' appearance, structure, confusing language, etc.), objective comprehension, and actionability. Demographic information for participants in each round is summarized in Table S1.

\section{Formative evaluation}

The primary goal of the formative evaluation was to identify and address the most serious usability problems with the reports, borrowing the definition of Lavery et al. ${ }^{34}$ "an aspect of the system and/or a demand on the user which makes it unpleasant, inefficient, onerous or impossible for the user to achieve their goals in typical usage situations." Given that typical goals when receiving a genetic report are to (1) understand the contents and (2) to take appropriate next steps if necessary (or to advise the patient of appropriate next steps), we treated as usability problems issues that caused confusion, left participants with incorrect impressions, generated unnecessary anxiety, or decreased the odds that a participant would be able to get the assistance they needed to take appropriate next steps. After rounds 2-3, interviewer notes and partial transcriptions of participants' answers to interview questions were reviewed and coded in MaxQDA to identify and evaluate the most significant problems, highlight 


\section{GENETIC TEST REPORT WHS}

Patient Details:

Name: John Doe

Date of birth: 18 March 1995

Sex: Male

NHS number: NH00198

Sample type: Blood
Test ordered by:

Name: Dr Requesta

Organisation: Alesford Hospital

Telephone: 01238555555

Copies to: Dr A. Nother

Dr X. Tra
Test carried out by:

Laboratory: $\quad$ Acurogen UK

Telephone: 01238666555

Date received: 26 February 2018

Date reported: 12 March 2018

Authorised by: A Tester

Reason for test: CF carrier status testing requested. Partner is a carrier of CF.

Your

Result

\section{Carrier of cystic fibrosis}

\section{ABOUT THE TEST}

This test looked at a gene called CFTR. Everyone has two copies of this gene (one from their mother and one from their father). Alterations to this gene can cause the condition cystic fibrosis (CF).

If you have an alteration in both copies of your CFTR genes you will have CF.

If you have an alteration in only one copy of CFTR you will not have CF but will be a 'carrier'.

Carriers are healthy but may pass on their altered gene to any children.

\section{WHAT THIS RESULT MEANS FOR YOU}

The test found that you have an alteration in one copy of your CFTR genes, making you a carrier of CF.

If you have children with someone who is also a carrier of CF, there is a 1 in 4 (25\%) chance in each pregnancy that the child will have CF.

If you have children with someone who has not been tested for CF, there is less than 1 in 100 (less than 1\%) chance that those children will have CF (some risk remains as your partner may be a carrier but not know).

In the UK population, around 1 in 25 (4\%) people are carriers of CF. Because you are a carrier of CF, your close relatives have an increased chance of also being CF carriers, so carrier testing can now be offered to your adult relatives.

\section{NEXT STEPS}

- You can be referred to the Clinical Genetics Service to discuss your options when planning a family. Please ask your doctor for this referral if it has not been made. Take this report with you to any appointments.

- If your relatives would like to be tested, they should ask their GP about CF carrier testing.

\section{MORE INFORMATION AND SUPPORT}

The results of a genetic test can be upsetting and difficult to take in.

If you have questions about your test result, talk to the doctor who ordered your test or phone the East Anglian Clinical Genetics Service on 01238216446 . Your doctor can also phone this number for advice and to help answer your queries.

To understand more about genetic testing, visit: www.nhs.uk/conditions/genetics/services/

To understand more about cystic fibrosis, visit: www.cysticfibrosis.org.uk/ or phone 01238373100

Fig. 1 Patient-friendly page of user-centered "Positive/Partner p.Phe508del" report. 
cases of poor comprehension, and assess the degree to which the reports met participants' information needs. Full coding and partial transcription from interview recordings were completed post hoc for round 1, but interviewer notes were reviewed and usability problems were enumerated and corrected prior to round 2 nevertheless. Our stop criterion for how many rounds of interviewing to conduct was that by the final round, no major usability problems should remain. Major usability problems are those for which "the user will probably use or attempt to use the product, but will be severely limited in his or her ability to do so"; ${ }^{35}$ we considered these to include issues that could leave recipients with a serious misconception.

Because we ultimately wished to run a summative evaluation focusing on subjective comprehension, risk probability comprehension, and communication efficacy, we categorized participant answers to questions intended to highlight usability issues that might affect these constructs in particular, as well as more exploratory constructs of interest (e.g., actionability, the degree to which "consumers of diverse backgrounds and varying levels of health literacy can identify what they can do based on the information presented"36). These questions were asked to help determine whether there were problems in any of these domains so severe as to constitute a major usability problem.

\section{Summative evaluation}

Interviews were followed by an experiment in which participants were given either the new (2-page) usercentered report or a standard (1-page) report currently in clinical use (and representative of standard practice). Our approach was to provide participants with the entire usercentered report, but to ask questions specific to the first page of the report to ensure that the patient-facing page was the one being evaluated. After receiving the participant information sheet, a consent form, and background information about cystic fibrosis, study participants were presented with a clinical scenario in which a hypothetical John and Jane Doe are thinking about starting a family. Neither has cystic fibrosis, but CF runs in Jane's family and she is known to be a carrier, so John's general practitioner (GP) has advised him to have a carrier test to inform the couple's family planning decisions. Participants were then shown a copy of "John's report," a report filled in with fictional information about $\mathrm{Mr}$. Doe, and asked to read it carefully. The report shown was either one of the standard reports described earlier, or one of the new user-centered reports. The evaluation therefore had a $2 \times 2$ factorial between-participants design with two levels of design (standard and user-centered) and two levels of test result (positive and negative). Afterward, participants completed a questionnaire collecting outcome measures. On every questionnaire page, text stated "Please answer the following based on what you have learned from the first page of the report. To take another look at it, you may click here"; clicking brought up the first page of the report. Note that basic background information about cystic fibrosis was provided to bring the experimental scenario closer to a typical real-world scenario. This was not done within the reports themselves, as in the real world a couple with $\mathrm{CF}$ in one partner's family would typically be aware of what CF is, particularly after meeting with a GP and being referred for testing.

\section{Key outcomes were subjective comprehension, risk probability comprehension, and communication efficacy} Subjective comprehension was assessed by asking "How well did you understand the information in the first page of the report?" and "How clear is the information on the first page of the report?" on a seven-point scale ranging from 1 ("not at all") to 7 ("completely"). Risk probability comprehension was assessed by tallying the number of risk probability comprehension questions answered correctly out of seven presented, counting responses within $\pm 1 \%$ of the correct answer as "correct." An investigator blinded to condition converted free-text responses to numbers. Communication efficacy was assessed using a version of the 18-item questionnaire developed by Scheuner et al., ${ }^{16}$ modified so as to be appropriate for laypersons rather than clinicians (Table 1). A power analysis suggested 192 participants were required to achieve $80 \%$ power to detect an effect size $f$ of 0.25 with intent to test main effects and two-way interactions via analysis of variance (ANOVA). Alpha was adjusted to 0.01, two-tailed, permitting us to look for differences in the three key outcomes described earlier at an $\alpha$ of 0.05 with adjustment for multiple hypothesis testing. Normality of residuals was assessed using the Shapiro-Wilk test ( $\alpha=0.05)$.

ANOVA is fairly robust to violations of normality, but for severe violations nonparametric alternatives are sometimes applied. For example, the Mann-Whitney test compares the mean ranks of two samples, where the rank of a value is determined by ranking all values from low to high regardless of sample. Power analysis indicated that if this were used to compare the user-centered and standard reports on any of our key dependent variables, 192 participants would yield $78 \%$ power to detect a medium-sized effect $(d=0.5, \alpha=0.01)$. The Scheirer-Ray-Hare extension of the Kruskal-Wallis test ${ }^{37}$ is a nonparametric ANOVA alternative based on ranks rather than means; 192 participants would provide $78 \%$ power to detect medium-sized main effects $(f=0.25, \alpha=0.01)$.

Forty-eight participants were randomized by the Qualtrics survey distribution software to each combination of design (standard and user-centered) and test result (positive and negative), excepting positive user-centered, which had 49 due to a glitch with Prolific. "Difficult" risk probability comprehension questions always followed "easy" questions, but the order in which questions were presented was otherwise counterbalanced by question type (Table 2). Our minimum acceptable goal for the evaluation was to outperform the standard template on at least one key outcome without being inferior on the other two, although we hoped to outperform it significantly on all measures. Tests were two-sided with Bonferroni correction for multiple hypothesis testing. 
Table 1 Scores for the standard and user-centered reports ${ }^{a}$

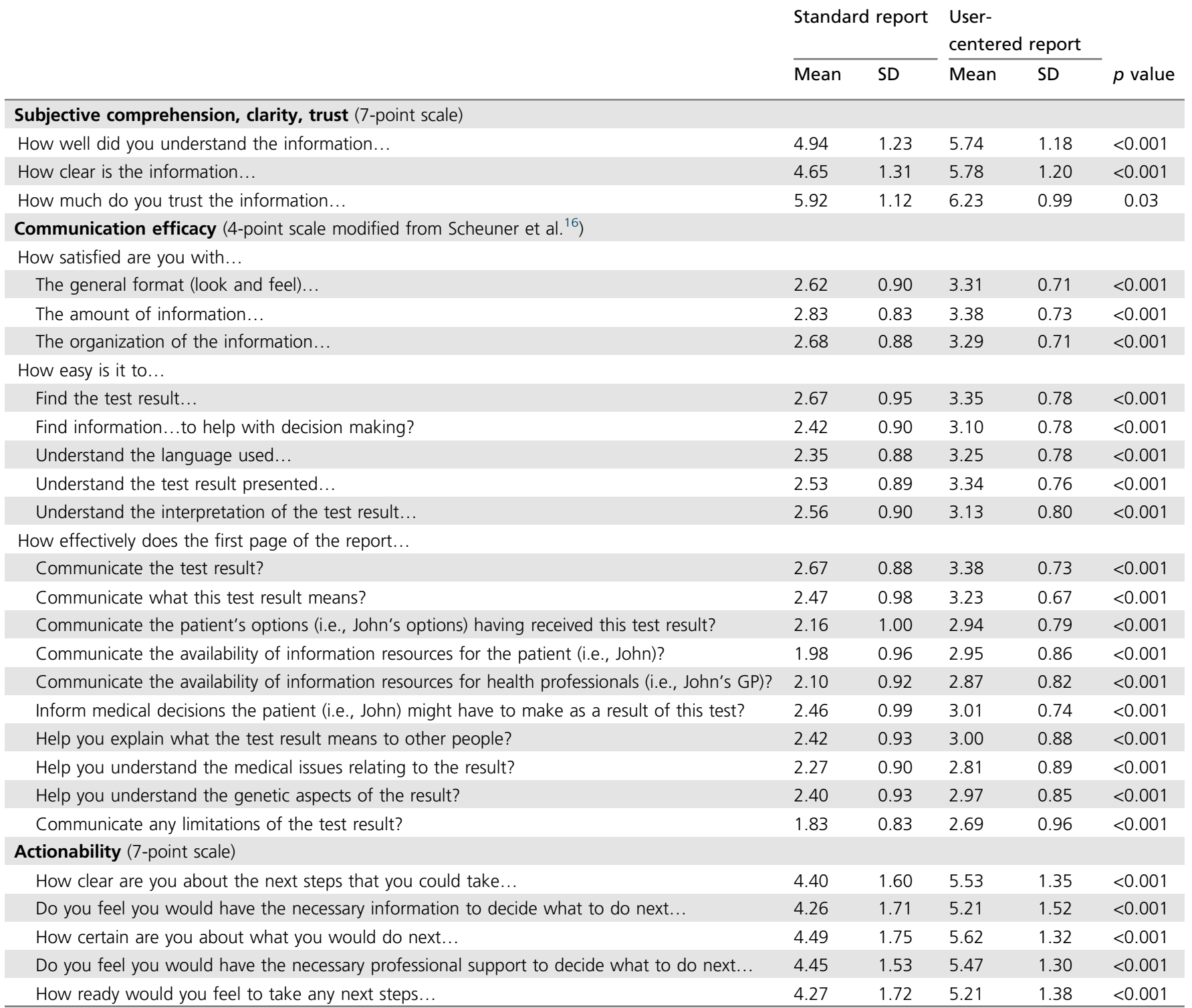

${ }^{a}$ To make the table more compact, ellipses ("...") appearing in communication efficacy questions and subjective understanding/clarity/trust questions stand in for the phrase "in the first page of the report" ("of the first page of the report," communication efficacy question 1). Ellipses appearing in actionability questions stand in for the phrase "if you had received this report in real life."

Measures of central tendency reported in "Results" are means, unless otherwise stated.

A secondary goal was to achieve superiority on at least one measure (without being inferior on any measure), out of all measures recorded. This included not only key outcomes, but also five exploratory measures: trust, actionability, risk probability interpretation, visibility of result summary, and ease of understanding the result summary. Trust was assessed by asking "How much do you trust the information in the first page of the report?" on a 7-point scale from 1 ("not at all") to 7 ("completely"), and five questions related to actionability were included (Table 1). Two risk probability interpretation questions were included- "Is John a carrier of cystic fibrosis?" and "If John and Jane have a child, will the child have cystic fibrosis?"-with multiple-choice answers (definitely not, unlikely, likely, and definitely). This provides insight into how people understand the numbers, but we had no goal beyond ensuring that viewers of positive reports did not conclude that the couple would "definitely" or "definitely not" have a child with CF, and that viewers of negative reports did not conclude that the couple would "likely" or "definitely" have a child with CF. This is because there is no right answer with respect to whether a $25 \%$ chance of having a child with cystic fibrosis feels "unlikely" or all too "likely." Participants were asked whether they had noticed the result summary (the "Your Result" box for the user-centered report, or the analogous "Summary" statement for the standard report) and how easy the result was to understand (from 1 "not at all 
Table 2 Measures of participant comprehension of risk probabilities

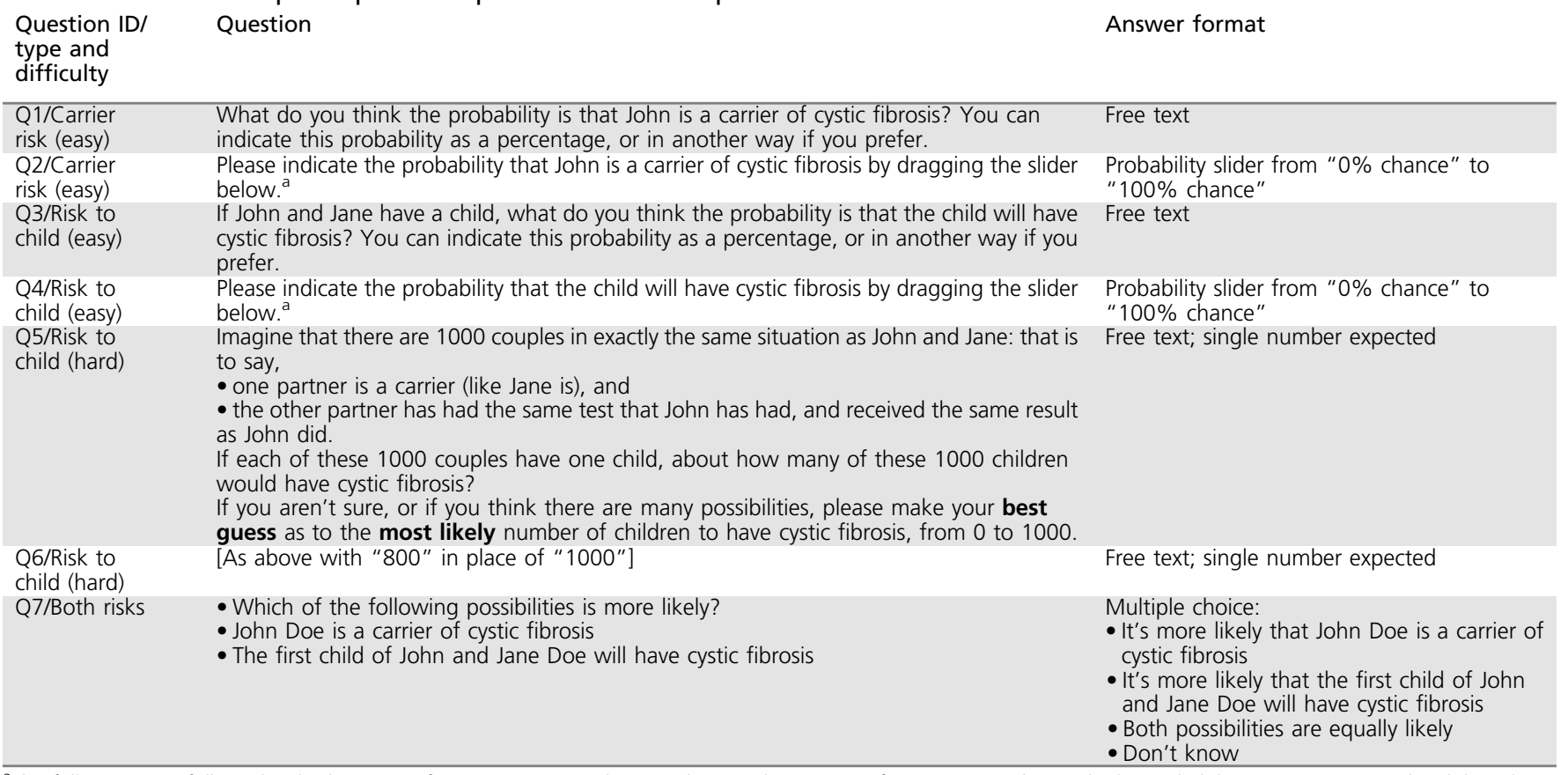

aThe following text followed in both cases: "If you aren't sure, please make your best guess. If you can't mark exactly the probability you want using the slider, please put it as close to that probability as you can."

easy" to 7 "very easy"). Finally, subjective numeracy ${ }^{38}$ was collected, as well as demographic information.

\section{RESULTS}

\section{Formative evaluation}

Quantitative summaries of participant responses to questions relating to subjective comprehension, risk probability comprehension, communication efficacy, and actionability are provided in Figs. S5-S9 and Table S3. Answers to these questions suggested adequate comprehension of the version 3 reports, at least in our small sample of ten participants (Table S3). A summary of changes made after each round of testing is available in Tables S4 and S5, and qualitative description of usability problems in each round and severity classifications are given in Table S6, with nothing rising to the level of a major usability problem by the final round. Formative evaluation was therefore stopped at this point and a summative evaluation was conducted for the version 3 partner reports. A full analysis of all substantive participant comments is beyond the scope of this paper, but a few examples of how specific usability issues led to specific changes are detailed in Table S7.

One issue noted during round 3 was that multiple participants commented that they had not noticed the result summary box on their first read-through. This did not rise to the level of a usability problem as these participants all read and understood the description of the result in the "What This Result Means For You" section, but it was of sufficient concern that visibility of result summary was added to the summative evaluation as an exploratory measure.

\section{Summative evaluation}

One hundred ninety-three participants were paid $£ 1.96 /$ person to complete the study via Prolific Academic; demographic characteristics appear in Table S2. Due to violations of normality, Mann-Whitney $U$-tests were used rather than ANOVAs, comparing mean ranks between the two conditions.

Subjective comprehension was higher for the user-centered (UC) reports, whether participants were asked about understanding $\left(\mathrm{M}_{\mathrm{UC}}=5.74, \mathrm{SD}_{\mathrm{UC}}=1.18, \mathrm{M}_{\mathrm{standard}}=4.94\right.$, $\left.\mathrm{SD}_{\text {standard }}=1.23, \quad U=2896, p<0.001, d=0.7\right)$ or clarity $\left(\mathrm{M}_{\mathrm{UC}}=5.78, \quad \mathrm{SD}_{\mathrm{UC}}=1.20, \quad \mathrm{M}_{\text {standard }}=4.65, \quad \mathrm{SD}_{\text {standard }}=\right.$ 1.31, $U=2322, p<0.001, d=0.9)$. No differences were observed in risk probability comprehension $\left(\mathrm{M}_{\mathrm{UC}}=4.95\right.$, $\mathrm{SD}_{\mathrm{UC}}=2.30, \mathrm{M}_{\text {standard }}=4.94, \mathrm{SD}_{\text {standard }}=2.31, \quad U=4618$, $p=0.9, d=0.0$ ), and item-wise chi-squared tests revealed that no questions in Table 2 were answered correctly more frequently in one condition than the other. Like Scheuner et al., ${ }^{16}$ we compared the mean total scores on communication efficacy, finding higher scores for the usercentered reports $\left(\mathrm{M}_{\mathrm{UC}}=3.11, \mathrm{SD}_{\mathrm{UC}}=0.56, \mathrm{M}_{\mathrm{standard}}=2.41\right.$, $\left.\mathrm{SD}_{\text {standard }}=0.7, \quad U=2045, \quad p<0.001, d=1.1\right)$. Item-wise analyses found significant differences for each item in favor of the user-centered reports, all $p<0.001$ (Table 1). Analogous $U$-tests comparing positive versus negative reports were conducted, none of which found significant results.

User-centered reports trended slightly higher with respect to trust $\left(\mathrm{M}_{\mathrm{UC}}=6.23, \mathrm{SD}_{\mathrm{UC}}=0.99, \mathrm{M}_{\text {standard }}=5.92\right.$, $\left.\mathrm{SD}_{\text {standard }}=1.12, U=3874, p=0.03, d=0.3\right)$, nonsignificant after correction for multiple hypothesis testing. They were 


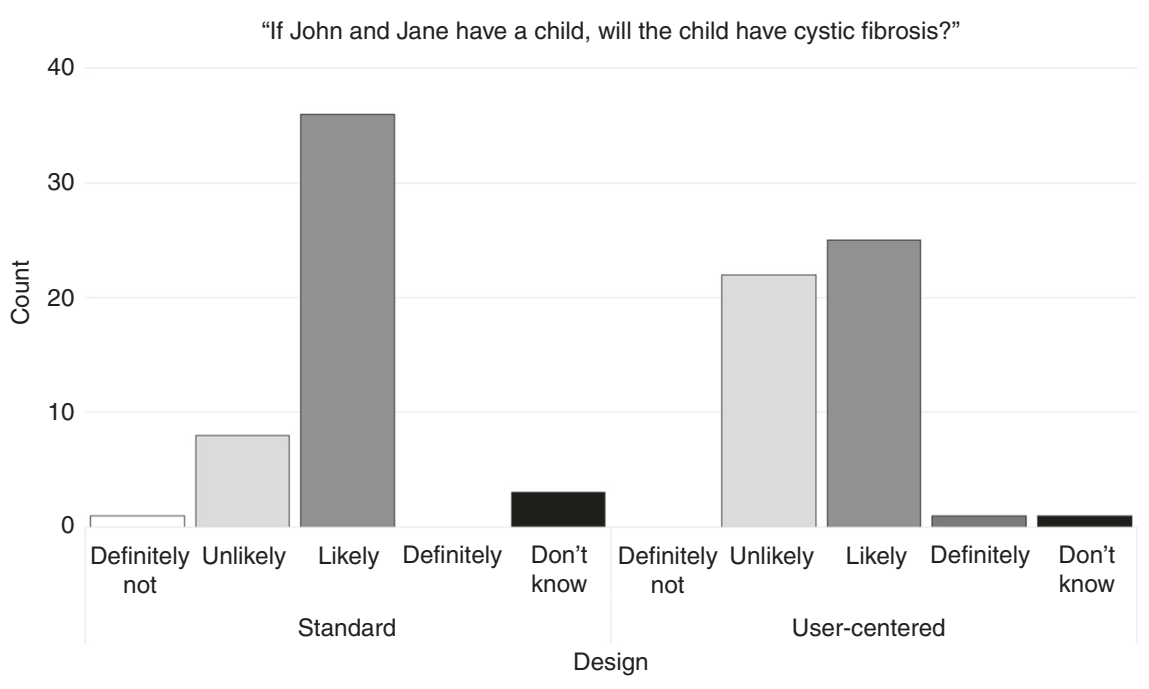

Fig. 2 Responses given by participants who viewed reports with positive test results to the question "If John and Jane have a child, will the child have cystic fibrosis?" When asked to produce the numeric probability that the first child would have cystic fibrosis (Table $\mathbf{2}$, Section 4), participants who felt it was "likely" that the first child would have cystic fibrosis had mean estimates of $34 \%(S D=21 \%)$ if they had seen the standard report, compared with $31 \%(S D=12 \%)$ if they had seen the user-centered report (no significant difference, $U=473, p=0.7)$. Participants who felt it was "unlikely" that the first child would have cystic fibrosis had mean estimates of $25 \%$ (SD $=0.4 \%$ ) if they had seen the standard report, compared to $27 \%$ (SD $=14 \%$ ) if they had seen the user-centered report (no significant difference, $U=100, p=0.4$ ).

reliably higher on actionability $\left(\mathrm{M}_{\mathrm{UC}}=5.41, \mathrm{SD}_{\mathrm{UC}}=1.20\right.$, $\mathrm{M}_{\text {standard }}=4.37, \mathrm{SD}_{\text {standard }}=1.47, U=2733, p<0.001, d=$ 0.8 ), with item-wise analyses favoring the new reports on every question (Table 1). Surprisingly, $27 \%$ reported that they had not noticed the result summary in the user-centered reports versus $8 \%$ in the standard reports, $\mathrm{X}^{2}(1, N=193)=$ $10.1, p=0.001$. However, estimates of John's probability of being a carrier (Table 2, question 2) were no different, suggesting that this information was clear even to those who missed the summary (positive reports: median 100\% both conditions, $\quad \mathrm{M}_{\mathrm{UC}}=0.86, \quad \mathrm{SD}_{\mathrm{UC}}=0.29, \quad \mathrm{M}_{\text {standard }}=0.80$, $\mathrm{SD}_{\text {standard }}=0.32, U=1170, p>0.9, d=0.2$; negative reports: median $1 \%$ both conditions, $\mathrm{M}_{\mathrm{UC}}=0.07, \quad \mathrm{SD}_{\mathrm{UC}}=0.16$, $\mathrm{M}_{\text {standard }}=0.07, \quad \mathrm{SD}_{\text {standard }}=0.16, \quad U=1161, \quad p>0.9, d=$ $0.0)$. The user-centered reports' result summaries were also rated easier to understand, $\mathrm{M}_{\mathrm{UC}}=6.05, \mathrm{SD}_{\mathrm{UC}}=1.33$, $\mathrm{M}_{\text {standard }}=5.00, \quad \mathrm{SD}_{\text {standard }}=1.66, \quad U=2876, \quad p<0.001$, $d=0.7$.

When estimating the probability that the first child would have cystic fibrosis (Table 2, question 4), there were no significant differences between levels of design for either positive reports (median 25\% both conditions; $\mathrm{M}_{\mathrm{UC}}=0.31$, $\mathrm{SD}_{\mathrm{UC}}=0.16, \mathrm{M}_{\text {standard }}=0.33, \mathrm{SD}_{\text {standard }}=0.19, \quad U=1328$, $p=0.2, d=-0.2$ ) or negative reports (median $1 \%$ both conditions; $\quad \mathrm{M}_{\mathrm{UC}}=0.10, \quad \mathrm{SD}_{\mathrm{UC}}=0.17, \quad \mathrm{M}_{\text {standard }}=0.06$, $\left.\mathrm{SD}_{\text {standard }}=0.11, U=1100, p=0.8, d=0.3\right)$. Nevertheless, responses to the risk interpretation questions suggested possible differences in the interpretation of these numbers (Fig. 2) for those who had been shown the positive reports, with those who saw the user-centered positive report more apt to say that a child of two carriers was "unlikely" to have cystic fibrosis than those who saw the standard positive report, $\mathrm{X}^{2}(1$, $N=97)=7.8, p=0.005$. Overall performance with respect to the goals of the evaluation is summarized in Table S8.

Despite the violations of normality, $2 \times 2$ ANOVAs crossing design with test result as well as the Scheirer-Ray-Hare extension of the Kruskal-Wallis test were also run on our key dependent measures. In both cases the same main effects were found, with no significant interactions.

\section{DISCUSSION}

Our findings suggest that by starting with a patient-friendly generic report template and modifying it for a specific genetic test with a rapid user-centered design process, reports can be made that laypersons find significantly clearer, easier to understand, and more effective at communicating key information, including what they should do next (actionability). The improvements in actionability are particularly encouraging, as several interview participants noted that it is especially important that patients feel they understand "next steps," and that they feel they have adequate information and support to make follow-up decisions. We also saw cautions from the risk comprehension literature ${ }^{39}$ borne out in our qualitative results (Table 3). Although we found no differences in risk probability comprehension, performance was near ceiling, with a median of 6 of 7 questions correct for both the user-centered and standard reports. Furthermore, combining user-centered testing with quantitative evaluation led us to insights that would have been difficult to achieve without both methods. For example, some individuals noted that although they understood their results from reading the text of the report, they had missed the summary box titled 
Table 3 Recommendations and lessons learned Topic Recommendation

\begin{tabular}{|c|c|}
\hline \multirow[t]{3}{*}{ Design } & $\begin{array}{l}\text { Splitting the design process into two phases-one to } \\
\text { develop a generic template with key sections and } \\
\text { information that patients want from the results, and } \\
\text { one to populate that template with the specific } \\
\text { numbers and information for each type of test-may } \\
\text { provide an efficient way to produce large numbers of } \\
\text { report templates for medical test results. }\end{array}$ \\
\hline & $\begin{array}{l}\text { Test with users: recommendations from the literature } \\
\text { should not be applied blindly. For example, although } \\
\text { there are good reasons to present risk figures in } \\
\text { multiple formats as a general rule, in our case including } \\
\left.\text { "1 in } 25(4 \%)^{\prime} \text { and "1 in } 4 \text { ( } 25 \%\right)^{\prime} \text { in close proximity } \\
\text { caused confusion. User testing permitted us to address } \\
\text { the issue in a way that allowed us to continue following } \\
\text { the recommendation but also eliminated the confusion. }\end{array}$ \\
\hline & $\begin{array}{l}\text { Focus on recruitment of diverse representative end users } \\
\text { throughout the process. We benefited from multiple } \\
\text { perspectives of different user groups (health-care } \\
\text { providers, patients, and members of the public with } \\
\text { varying levels of experience of genetic testing), and } \\
\text { would have benefited from a more concerted effort to } \\
\text { recruit participants who were more diverse in other } \\
\text { ways (e.g., education). }\end{array}$ \\
\hline \multirow[t]{2}{*}{ Evaluation } & $\begin{array}{l}\text { Following up on comments from interviews with a } \\
\text { larger sample size can be a useful way to determine } \\
\text { whether an offhand comment ("I don't know how I } \\
\text { missed that!") is indicative of a larger issue ( } 27 \% \text { of } \\
\text { participants indicating that they did not see the result } \\
\text { summary box). }\end{array}$ \\
\hline & $\begin{array}{l}\text { Formative and summative evaluation both ought to be } \\
\text { applied to important patient-facing materials whenever } \\
\text { possible. }\end{array}$ \\
\hline \multirow[t]{3}{*}{$\begin{array}{l}\text { Vocabulary and } \\
\text { wording }\end{array}$} & $\begin{array}{l}\text { When using vocabulary that implies a change in risk } \\
\text { (e.g., reduce/increase), the risks being compared must } \\
\text { be clearly described. }\end{array}$ \\
\hline & $\begin{array}{l}\text { For patient-facing materials, "gene changes" is a poor } \\
\text { plain-English alternative to "variant," as it sometimes } \\
\text { led to misinterpretations (e.g., "What does it mean by } \\
\text { no cystic fibrosis gene changes detected? Can genes } \\
\text { change throughout the life course or something? I } \\
\text { thought you're kind of born with it or you're not.") In } \\
\text { our study, "alterations" seemed to be reasonably well } \\
\text { received and interpreted. }\end{array}$ \\
\hline & $\begin{array}{l}\text { Prior literature } 39 \text { has found that a quarter of people } \\
\text { incorrectly answer the question "Which of the following } \\
\text { numbers represents the biggest risk of getting a } \\
\text { disease? } 1 \text { in } 100,1 \text { in } 1000 \text {, or } 1 \text { in } 10 ? " \text { ? not realizing } \\
\text { that a larger number in the denominator corresponds to } \\
\text { a smaller probability. A quote from one of our } \\
\text { participants suggested she had a similar } \\
\text { misapprehension ("less than } 1 \text { in } 500 \text { sounds less scary, } \\
\text { because then you can think, oh, it could be } 400 \text { or } \\
200 " \text { ). When presenting probabilities that are intended } \\
\text { to be compared with each other, keep denominators } \\
\text { constant to decrease the chances of misinterpretation, } \\
\text { i.e., compare } 1 \text { in } 1000 \text { with } 6 \text { in } 1000 \text { rather than } \\
\text { comparing } 1 \text { in } 1000 \text { with } 1 \text { in } 167 \text {. }\end{array}$ \\
\hline
\end{tabular}

"Your Result." Therefore, we added a question investigating this to our quantitative evaluation, which confirmed that $27 \%$ of participants did not remember seeing this box. Thus, even anecdotal evidence from small qualitative studies can generate important hypotheses that can then be tested more rigorously.

One limitation of our formative evaluation was that participants were overwhelmingly female (80\%) and highly educated (Table S1). Our summative evaluation sample had similar biases ( $\sim 69 \%$ female, $\sim 56 \%$ university-educated), among other differences from the UK population (Table S2). Although subgroup analysis demonstrated that the benefits of our novel templates were thankfully not restricted to women, nor to the highly educated or highly numerate (Table S9), our development process could have identified important issues more quickly if we had solicited input from a more diverse group of participants from the outset. Given this nonrepresentative sample and the fact that it was more difficult to see the result summary in our report than in the standard report, we have made one additional change to address this, and are planning a replication of our summative evaluation with this new report using census-matched cross-stratified quota sampling.

Another drawback is that the use of a hypothetical scenario with our testing group means that our results are less likely to generalize than if they had been conducted as part of a clinical study. (See Stuckey et al., ${ }^{26}$ Williams et al. ${ }^{28}$ for examples of patient-facing work that does not suffer from this limitation.) Furthermore, this study was limited to a single autosomal recessive condition. We have planned future research on reports for $B R C A 1 / B R C A 2$ testing, which will investigate whether the benefits of this approach generalize to material that is more challenging to communicate.

Overall, our experience demonstrated that a user-centered approach can be extremely helpful in discovering and rectifying usability problems with genetic reports. We hope that this research illustrates how rapid user-centered design can be used to develop more comprehensible and actionable reports, and that building on templates developed via usercentered design may be useful in developing patient-facing materials more generally.

\section{SUPPLEMENTARY INFORMATION}

The online version of this article (https://doi.org/10.1038/s41436019-0649-0) contains supplementary material, which is available to authorized users.

\section{ACKNOWLEDGEMENTS}

This work was supported by the David \& Claudia Harding Foundation via the Winton Centre for Risk and Evidence Communication, sponsored by the University of Cambridge. A. C. is funded by Health Education England. The authors also thank George Farmer, Harry Gray, Yorkshire and North East Genomic Laboratory Hub Central Laboratory, Beverley Speight (Principal Genetic Counsellor, Cambridge University Hospitals NHS Foundation Trust), Ed Thompson, Steve Abbs, and Leila Finikarides.

\section{CODE AVAILABILITY}

Code and data for primary analyses, as well as additional exploratory analyses not reported here, are available at https:// github.com/WintonCentre/cf_reports (ver. 2019.07.22).

\section{DISCLOSURE}

G.C. owns shares in companies related to genetics (Personalis, Petagene), as does her husband (Sophia Genetics); none of these companies are involved in CF reporting. The other authors declare no conflicts of interest.

Publisher's note Springer Nature remains neutral with regard to jurisdictional claims in published maps and institutional affiliations. 


\section{REFERENCES}

1. NHS England Medical Directorate, Graham E. Improving outcomes through personalised medicine. 2016. https://www.england.nhs.uk/wp-content uploads/2016/09/improving-outcomes-personalised-medicine.pdf. Accessed 9 September 2019.

2. Haga SB, Mills R, Pollak KI. Developing patient-friendly genetic and genomic test reports: formats to promote patient engagement and understanding. Genome Med. 2014;6:58

3. Sandhaus LM, Singer ME, Dawson NV, Wiesner GL. Reporting BRCA test results to primary care physicians. Genet Med. 2001;3:327-334.

4. McGovern MM, Benach M, Zinberg R. Interaction of genetic counselors with molecular genetic testing laboratories: implications for non-geneticist health care providers. Am J Med Genet. 2003; 119A:297-301.

5. Ostergren JE, Gornick MC, Carere DA, et al. How well do customers of direct-to-consumer personal genomic testing services comprehend genetic test results? Findings from the impact of personal genomics study for the PGen Study Group. Public Health Genomics. 2015;18:216-224.

6. Joseph G, Pasick RJ.Schillinger D, et al. Information mismatch: cancer risk counseling with diverse underserved patients. J Genet Couns.2017.

7. Rehm HL, Bale SJ, Bayrak-Toydemir P, et al. ACMG clinical laboratory standards for next-generation sequencing. Genet Med. 2013;15:733-747.

8. Claustres $M$, Kožich $V$, Dequeker $E$, et al. Recommendations for reporting results of diagnostic genetic testing (biochemical, cytogenetic and molecular genetic) on behalf of the ESHG Quality Committee. Eur J Hum Genet. 2014;22:160-170.

9. Lautenbach DM, Christensen KD, Sparks JA, Green RC. Communicating genetic risk information for common disorders in the era of genomic medicine. Annu Rev Genomics Hum Genet. 2013;14:491-513.

10. Chen B, Gagnon M, Shahangian S, Anderson NL, Howerton DA, Boone DJ. Good laboratory practices for molecular genetic testing for heritable diseases and conditions. MMWR Recomm Rep. 2009;58:1-37.

11. Matthijs $G$, Souche $E$, Alders $M$, et al. Guidelines for diagnostic nextgeneration sequencing. Eur J Hum Genet. 2016;24:2-5.

12. Bowdin $\mathrm{S}$, et al. Recommendations for the integration of genomics into clinical practice. Genet Med. 2016;18:1075-1084.

13. Tack V, Dufraing K, Deans ZC, Van Krieken HJ, Dequeker EMC. The ins and outs of molecular pathology reporting. Virchows Arch. 2017;471:199-207.

14. Haga SB. Educating patients and providers through comprehensive pharmacogenetic test reports. Pharmacogenomics. 2017; 18:1047-1050.

15. Krousel-Wood M, Andersson HC, Rice J, Rosner ER, Lubin IM, Jackson KE. Physicians' perceived usefulness of and satisfaction with test reports for cystic fibrosis $(\Delta \mathrm{F} 508)$ and factor $V$ Leiden. Genet Med. 2003;5:166-171.

16. Scheuner MT, Orlando Edelen M, Hilborne LH, Lubin IM. Effective communication of molecular genetic test results to primary care providers. Genet Med. 2013;15:444-449.

17. Lubin IM, Caggana M, Constantin C, et al. Ordering molecular genetic tests and reporting results practices in laboratory and clinical settings. J Mol Diagn. 2008;10:459-468.

18. Makhnoon S, Shirts BH, Bowen DJ, Fullerton SM. Hereditary cancer gene panel test reports: wide heterogeneity suggests need for standardization. Genet Med. 2018;20:1438-1445.

19. Messner DA, Koay P, Naber JAl, et al. Barriers to clinical adoption of nextgeneration sequencing: a policy Delphi panel's solutions. Per Med. 2018;14:339-354.

20. Shaer O, Nov O, Westendorf L, Ball M. Communicating personal genomic information to non-experts: A new frontier for human-computer interaction. Vol 11. Boston: Now Foundations and Trends; 2017. https://doi.org/10.1561/1100000067. Accessed 9 September 2019.

21. Vassy JL, McLaughlin HL, Macrae CA, et al. A one-page summary report of genome sequencing for the healthy adult. Public Health Genomics. 2015;18:123-129.

22. Scheuner MT, Hilborne L, Brown J, Lubin IM. A report template for molecular genetic tests designed to improve communication between the clinician and laboratory. Genet Test Mol Biomarkers. 2012;16:761-769.
23. Dorschner $\mathrm{MO}$, Amendola LM, Shirts $\mathrm{BH}$, et al. Refining the structure and content of clinical genomic reports. Am J Med Genet C Semin Med Genet. 2014;0:85-92.

24. Lubin IM, McGovern MM, Gibson Z, et al. Clinician perspectives about molecular genetic testing for heritable conditions and development of a clinician-friendly laboratory report. J Mol Diagn. 2009;11:162-171.

25. Cutting $E$, Banchero $M$, Beitelshees $A L$, et al. User-centered design of multi-gene sequencing panel reports for clinicians. J Biomed Inform. 2016;63:1-10.

26. Stuckey $H$, Williams $J L$, Fan $A L$, et al. Enhancing genomic laboratory reports from the patients' view: a qualitative analysis. Am J Med Genet A. 2015;167A:2238-2243.

27. Williams JL, Rahm AK, Stuckey $H$, et al. Enhancing genomic laboratory reports: a qualitative analysis of provider review. Am J Med Genet A. 2016;170A:1134-1141.

28. Williams M, Williams J, Rahm A, et al. Evaluating the impact of a userfriendly report of genetic testing results for parents of children with genetic disorders. Washington, D.C.: Patient-Centered Outcomes Research Institute (PCORI); 2018. https://doi.org/10.25302/9.2018. CD.13046987. Accessed 9 September 2019.

29. Williams MS, Kern MS, Lerch VR, Billet J, Williams JL, Moore GJ. Implementation of a patient-facing genomic test report in the electronic health record using a web-application interface. BMC Med Inform Decis Mak. 2018;18:1-9.

30. Shaer O, Nov O, Okerlund J, et al. Informing the design of direct-toconsumer interactive personal genomics reports. J Med Internet Res. 2015;17:e146.

31. Norman DA, Draper SW. User centered system design: New perspectives on human-computer interaction. Hillsdale, NJ: Erlbaum; 1986.

32. Gulliksen J, Göransson B, Boivie I, Blomkvist S, Persson J, Cajander Å. Key principles for user-centred systems design. Behav Inf Technol. 2003;22:397-409.

33. Tullis T, Albert B. Measuring the user experience: collecting, analyzing, and presenting usability metrics. 2nd ed. Waltham, MA: Elsevier; 2013.

34. Lavery D, Cockton G, Atkinson MP. Comparison of evaluation methods using structured usability problem reports. Behav Inf Technol. 1997; 16:246-266.

35. Rubin J. Handbook of usability testing: how to plan, design and conduct effective tests. New York: John Wiley \& Sons; 1994.

36. Shoemaker SJ, Wolf MS, Brach C. Development of the Patient Education Materials Assessment Tool (PEMAT): a new measure of understandability and actionability for print and audiovisual patient information. Patient Educ Couns. 2014;96:395-403.

37. Scheirer CJ, Ray WS, Hare N. The analysis of ranked data derived from completely randomized factorial designs. Biometrics. 1976;32: 429-434.

38. Fagerlin A, Zikmund-Fisher BJ, Ubel PA, Jankovic A, Derry HA, Smith DM. Measuring numeracy without a math test: development of the Subjective Numeracy Scale. Med Decis Mak. 2007;27:672-680.

39. Galesic M, Garcia-Retamero R. Statistical numeracy for health: a crosscultural comparison with probabilistic national samples. Arch Intern Med. 2010;170:462-468.

Open Access This article is licensed under a Creative Commons Attribution 4.0 International License, which permits use, sharing, adaptation, distribution and reproduction in any medium or format, as long as you give appropriate credit to the original author(s) and the source, provide a link to the Creative Commons license, and indicate if changes were made. The images or other third party material in this article are included in the article's Creative Commons license, unless indicated otherwise in a credit line to the material. If material is not included in the article's Creative Commons license and your intended use is not permitted by statutory regulation or exceeds the permitted use, you will need to obtain permission directly from the copyright holder. To view a copy of this license, visit http://creativecommons.org/licenses/ by/4.0/.

(C) The Author(s) 2019 